\title{
Spatiotemporal impact of antecedent drought on hot extremes from the nonstationary risk perspective: A case study in eastern China
}

\author{
Pengcheng $\mathrm{Xu}^{1}$, Dong Wang ${ }^{2}$, Yuankun Wang ${ }^{3}$, Vijay Singh ${ }^{4}$, Jianchun Qiu ${ }^{1}$, Jichun $\mathrm{Wu}^{2}$, \\ Along Zhang ${ }^{2}$, and Xiaopei $\mathrm{Ju}^{2}$
}

${ }^{1}$ Yangzhou University

${ }^{2}$ Nanjing University

${ }^{3}$ North China Electric Power University, Beijing, P.R. China

${ }^{4}$ Texas A \& M University

August 4, 2021

\begin{abstract}
Hot extremes may adversely impact human health and agricultural production. Owing to anthropogenic and climate changes, the close and dynamic interaction between drought and hot extremes in most areas of China need to be revisited from the perspective of nonstationarity. This study therefore proposes a time-varying Copula-based model to describe the nonstationary dependence structure of extreme temperature (ET) and antecedent soil moisture condition to quantify the dynamic risk of hot extremes conditioned on dry/wet condition. This study proposed a new approach to identify the soil moisture driving law over extreme temperature from the point view of tail monotonicity and nonstationary risk assessment. Owing to the LTI-RTD (left tail increasing and right tail decreasing) tail monotonicity for dependence structure of these two extremes derived from most areas, the driving laws of soil moisture over ET follows DDL1-WDL1 laws (DDL1: drier antecedent soil moisture condition would trigger a higher risk of ET; WDL1: wetter antecedent soil moisture condition would alleviate the occurrence risk of ET). Because of the spatiotemporal divergence of sensitivity index derived from tail monotonicity (SITM), we can conclude that the spatial and temporal heterogeneity of response degree of ET over the variations of antecedent dry/wet conditions is evident. Incorporation of nonstationarity and tail monotonicity helps identify the changes of driving mechanism (laws) between soil moisture and hot extremes. From the comparison of different kinds of nonstationary behaviours over the spatial distribution of conditional probability of ET (CP1), the dependence nonstationarity can impose greater variations on the spatial distribution of conditional risk of ET given antecedent dry condition (CP1).
\end{abstract}

\section{Hosted file}

$\mathrm{Xu}$ PC-Nonstationary riskassessment_Drought_2021_6-4.docx available at https://authorea. com/users/429035/articles/532779-spatiotemporal-impact-of-antecedent-drought-on-hotextremes-from-the-nonstationary-risk-perspective-a-case-study-in-eastern-china 


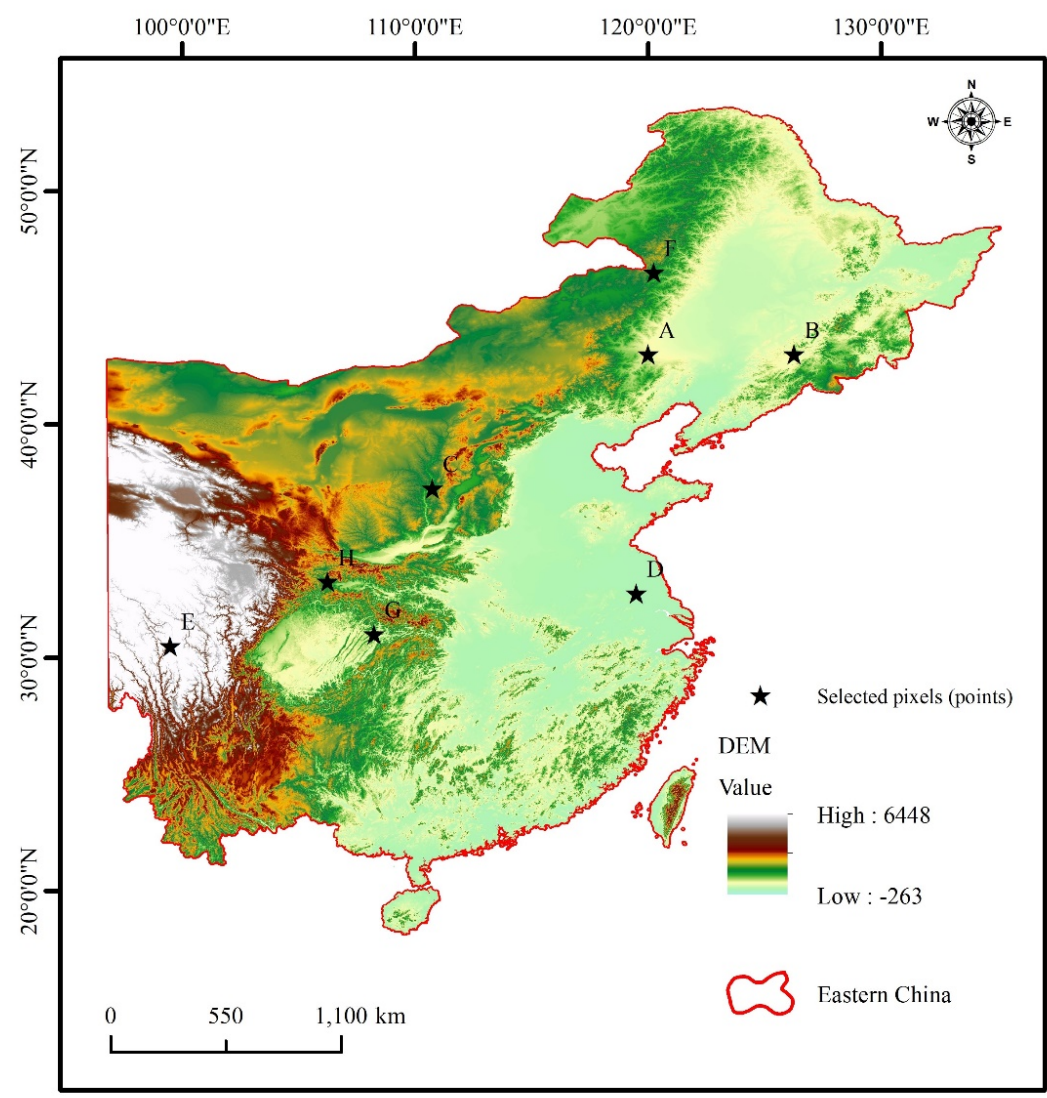



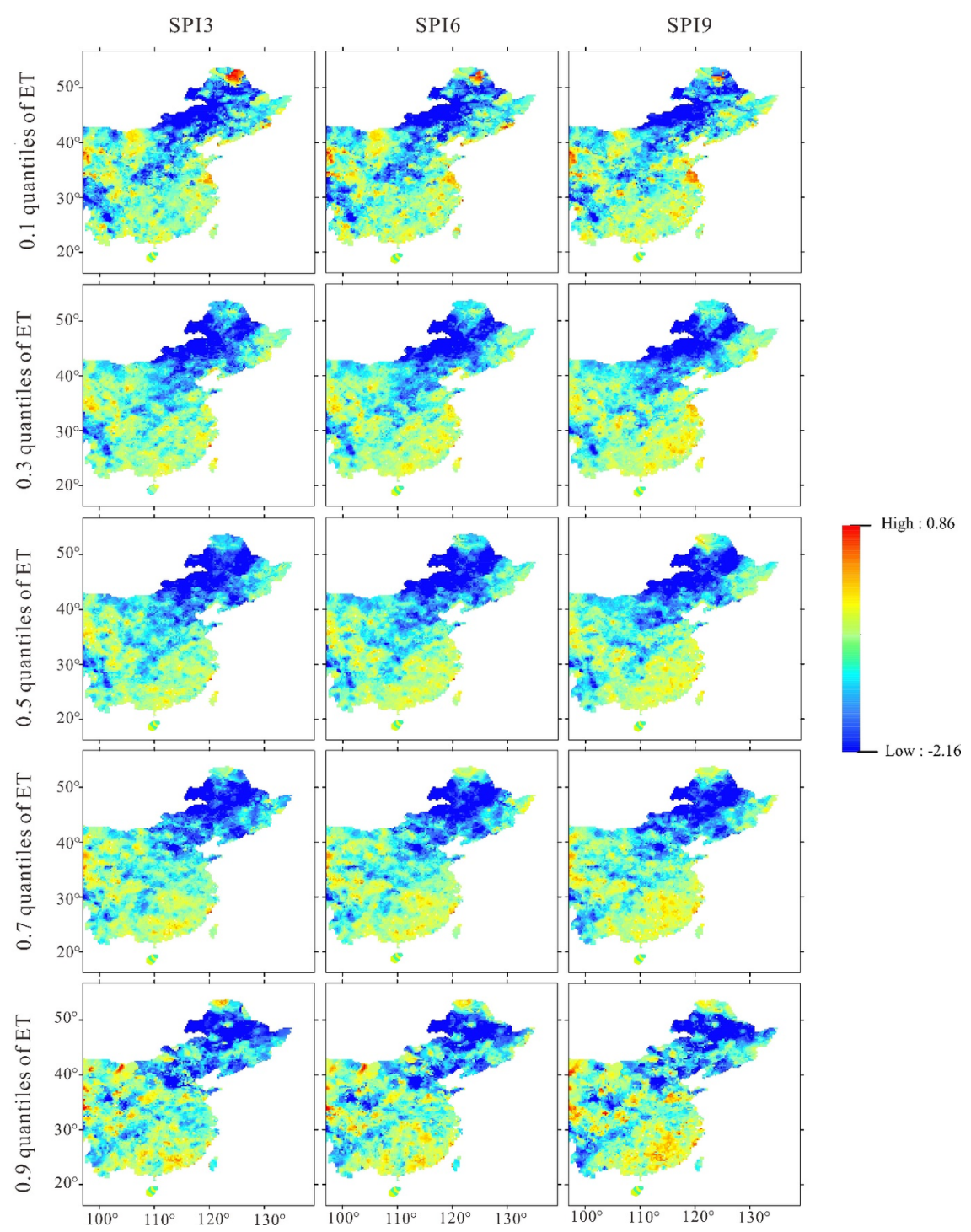


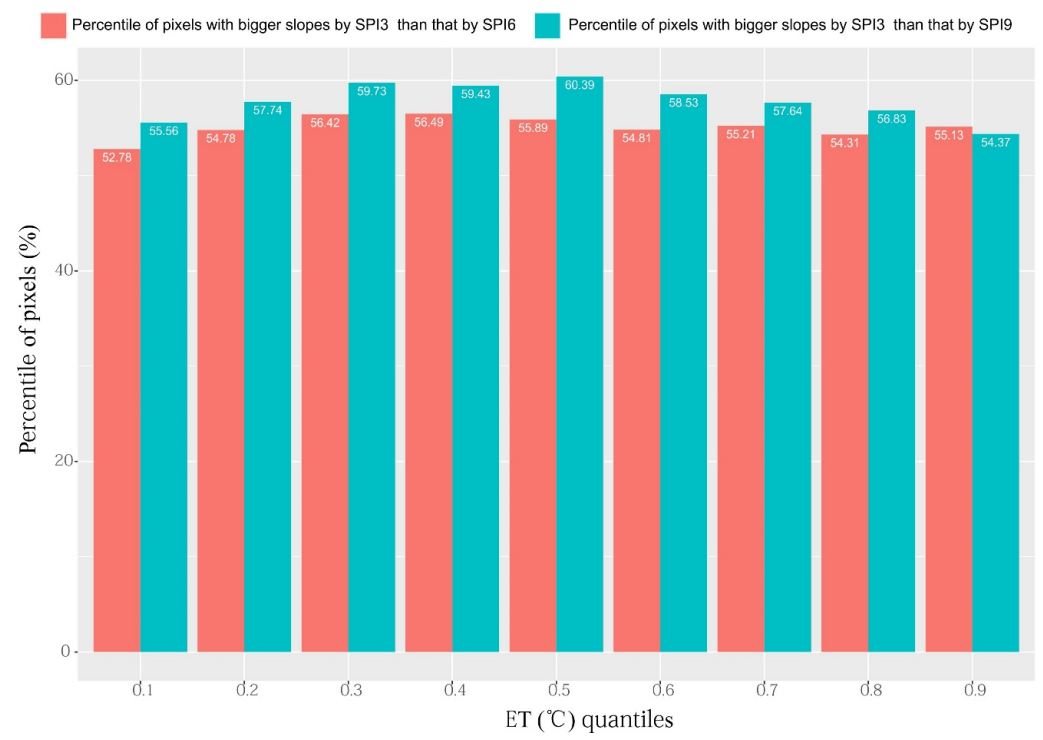



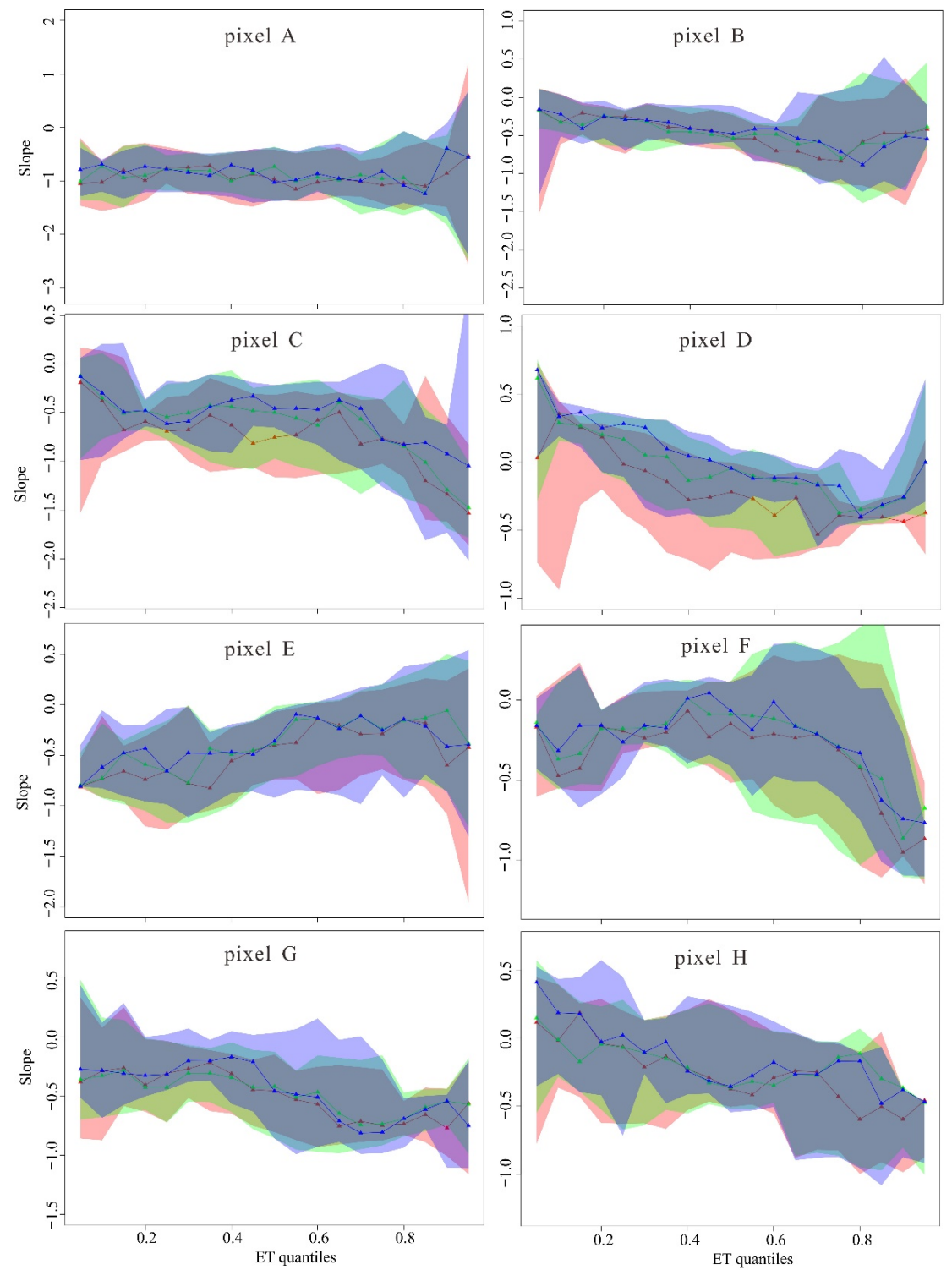

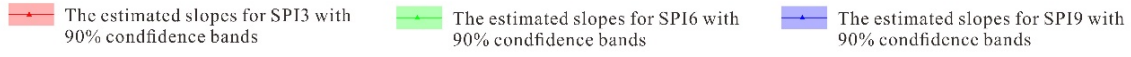




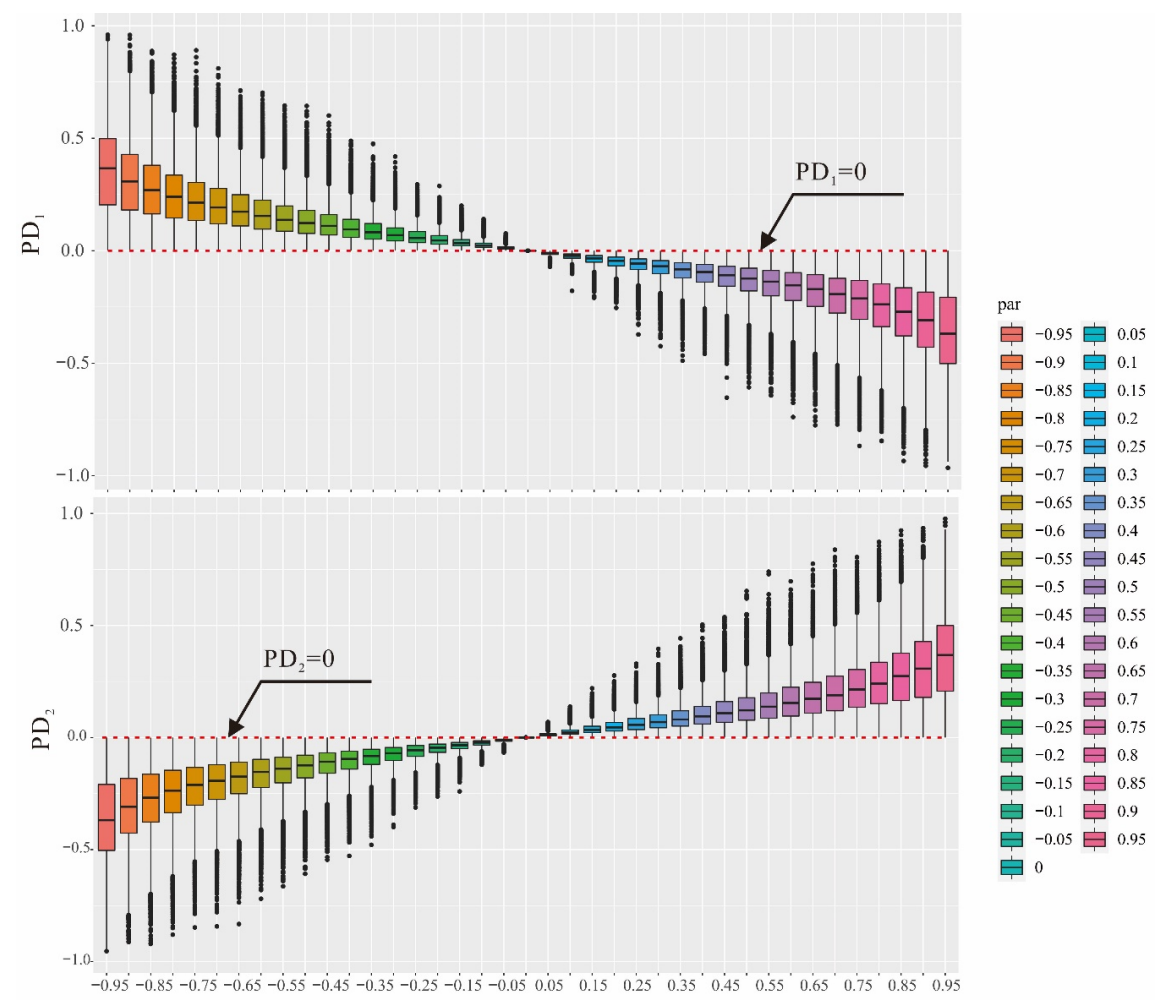

par
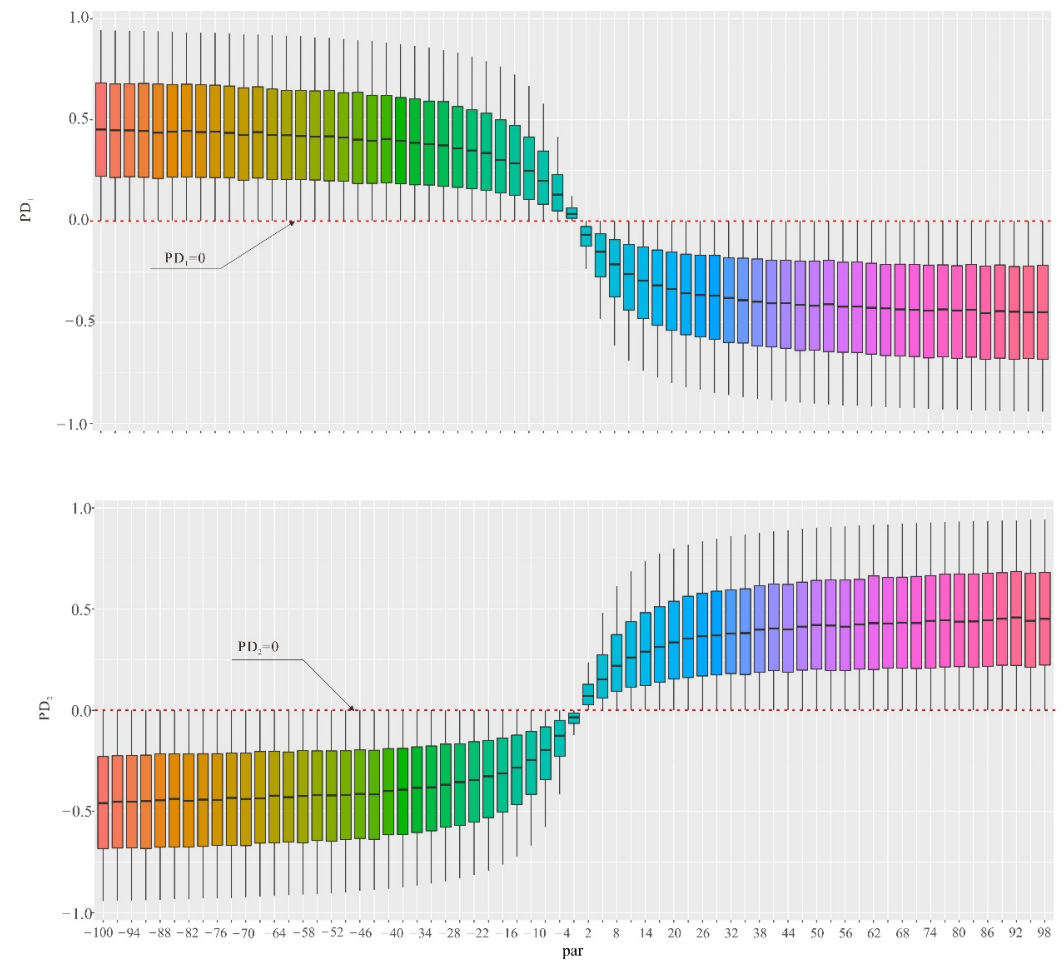

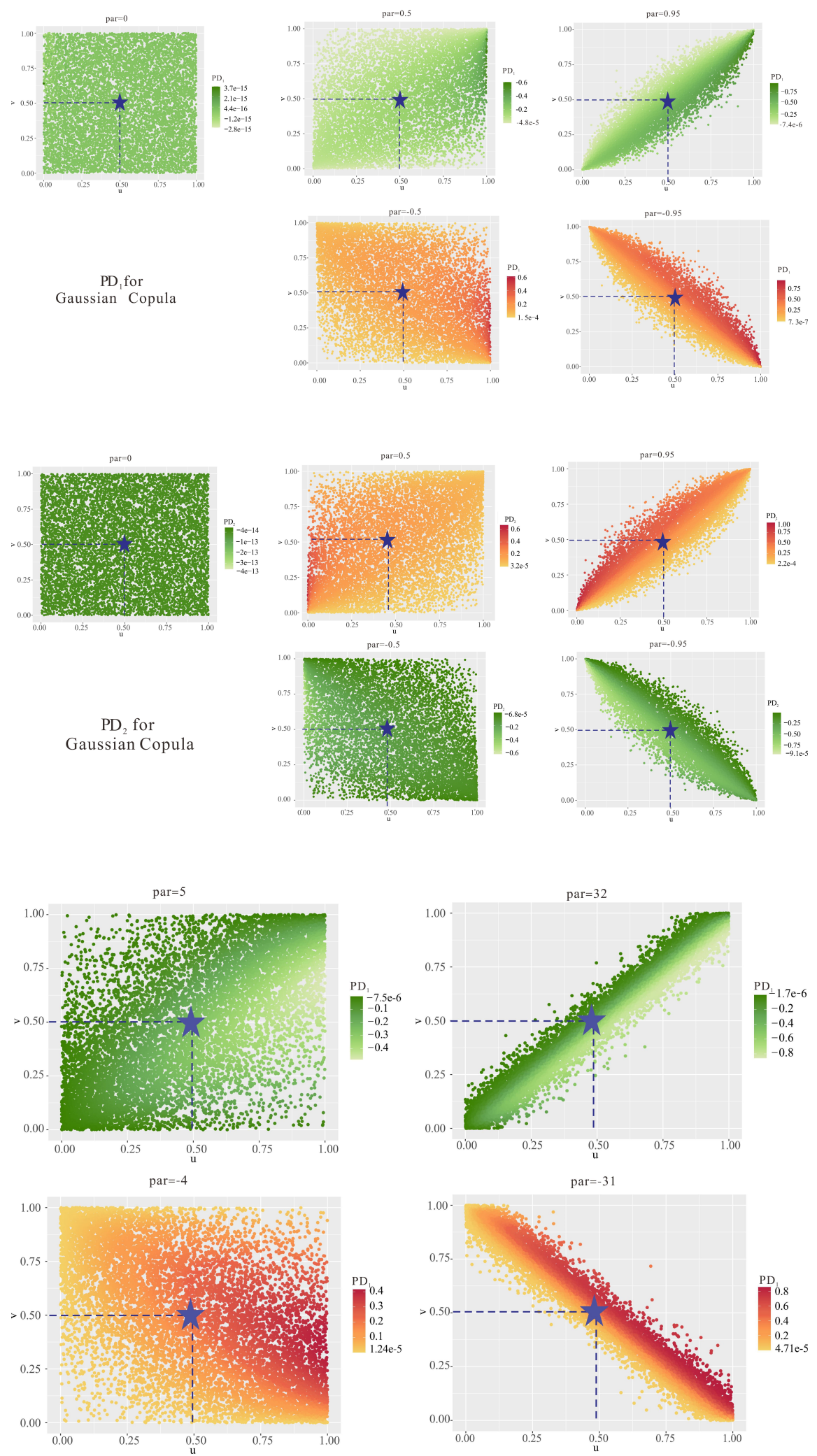

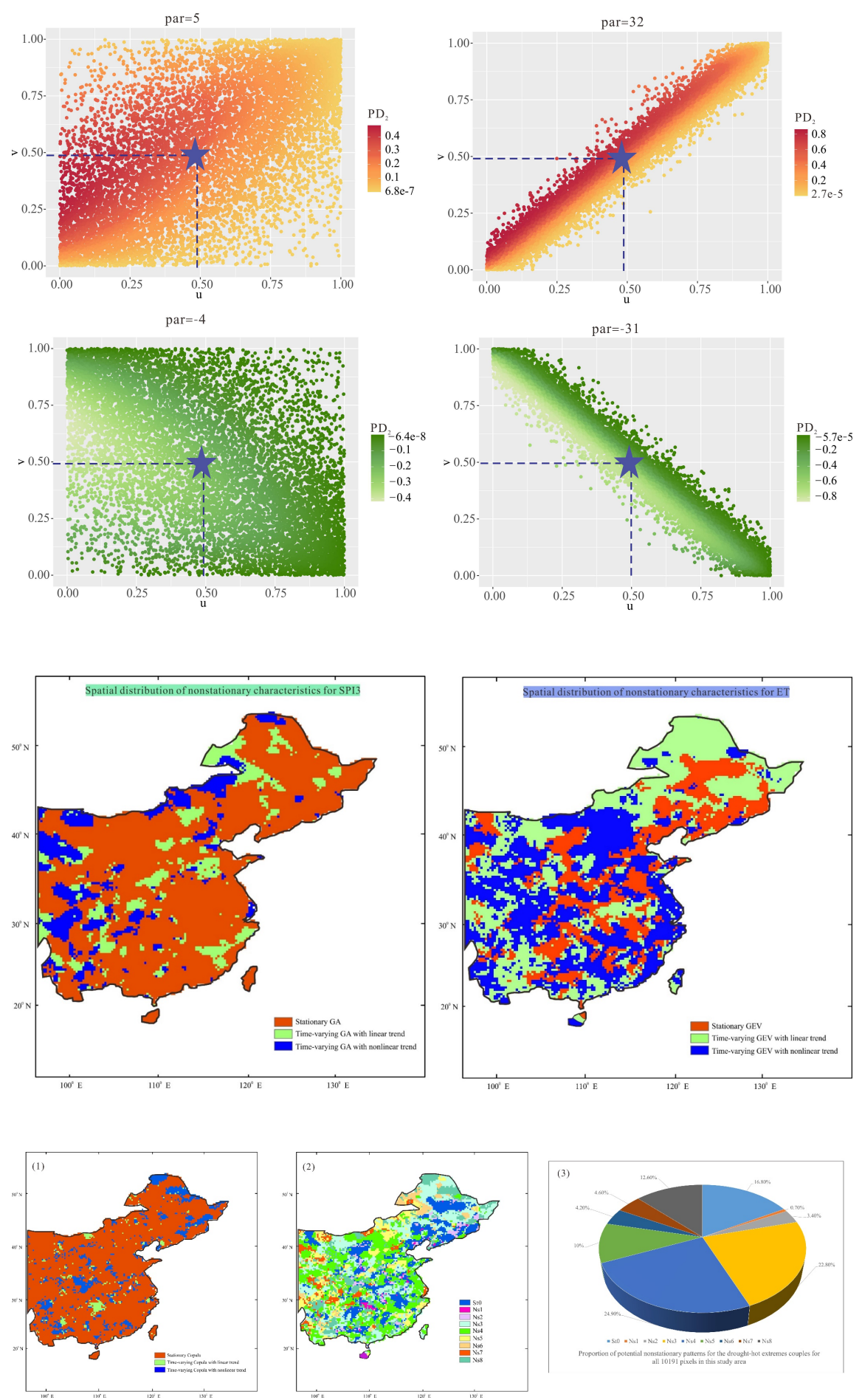


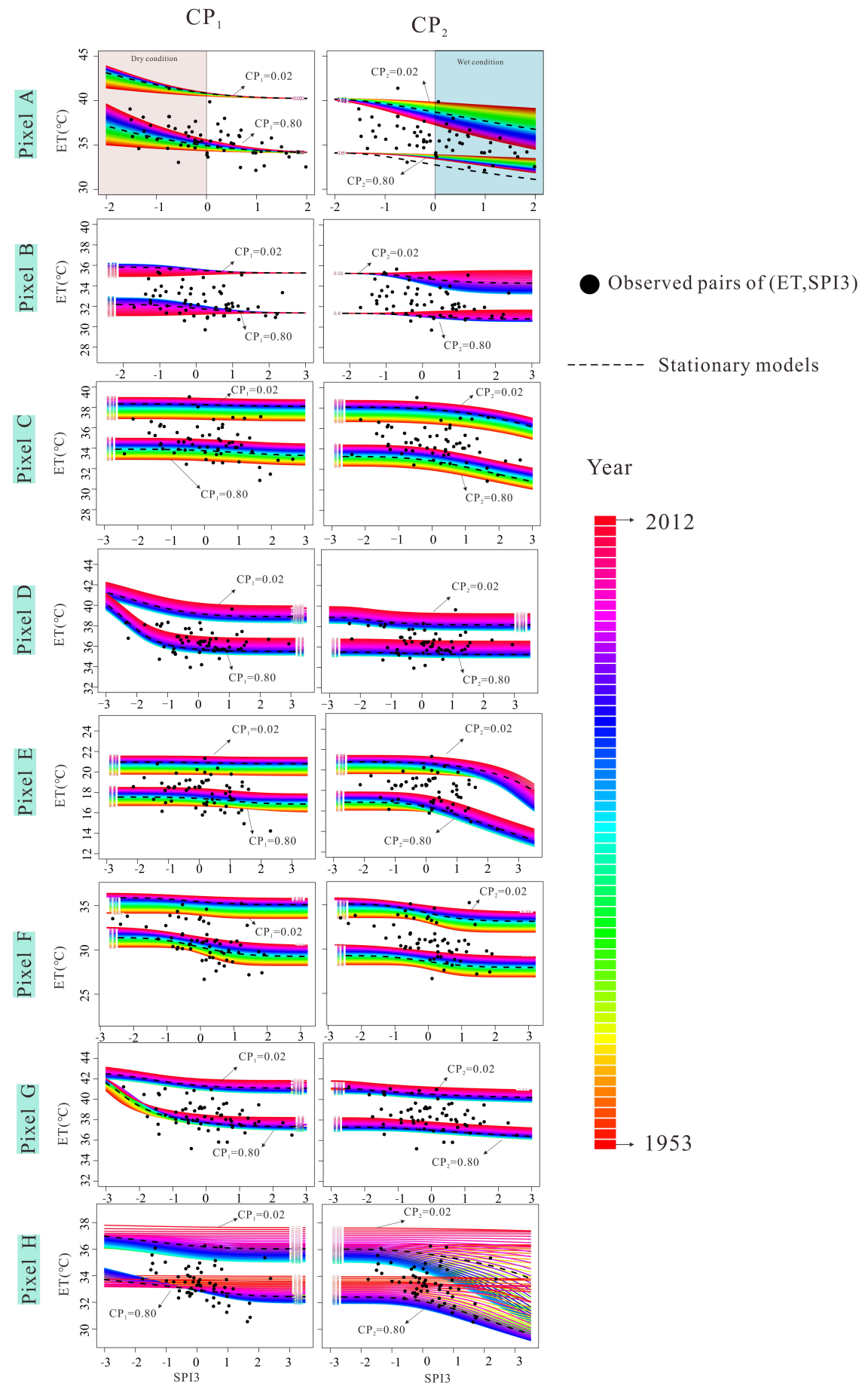



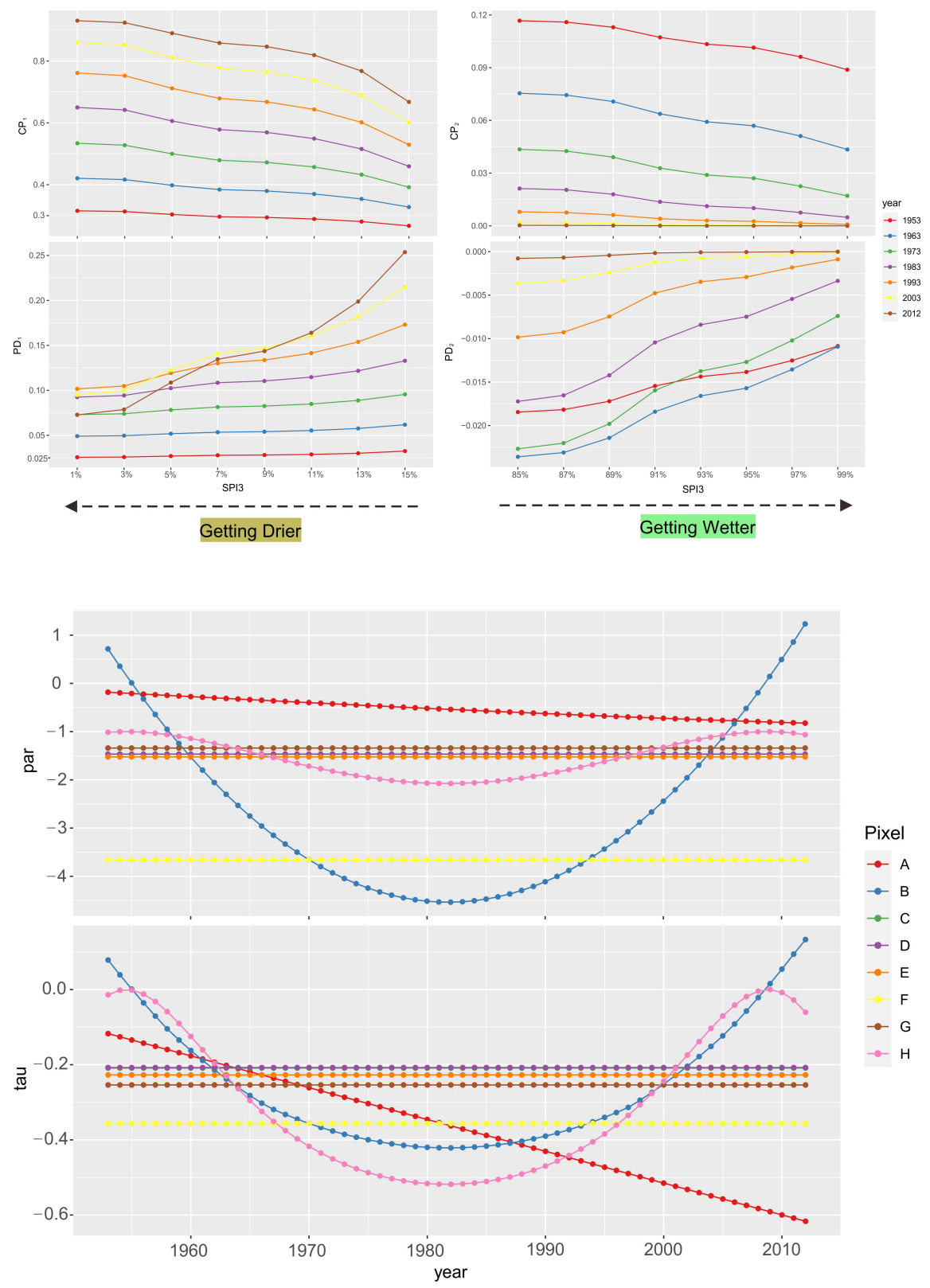

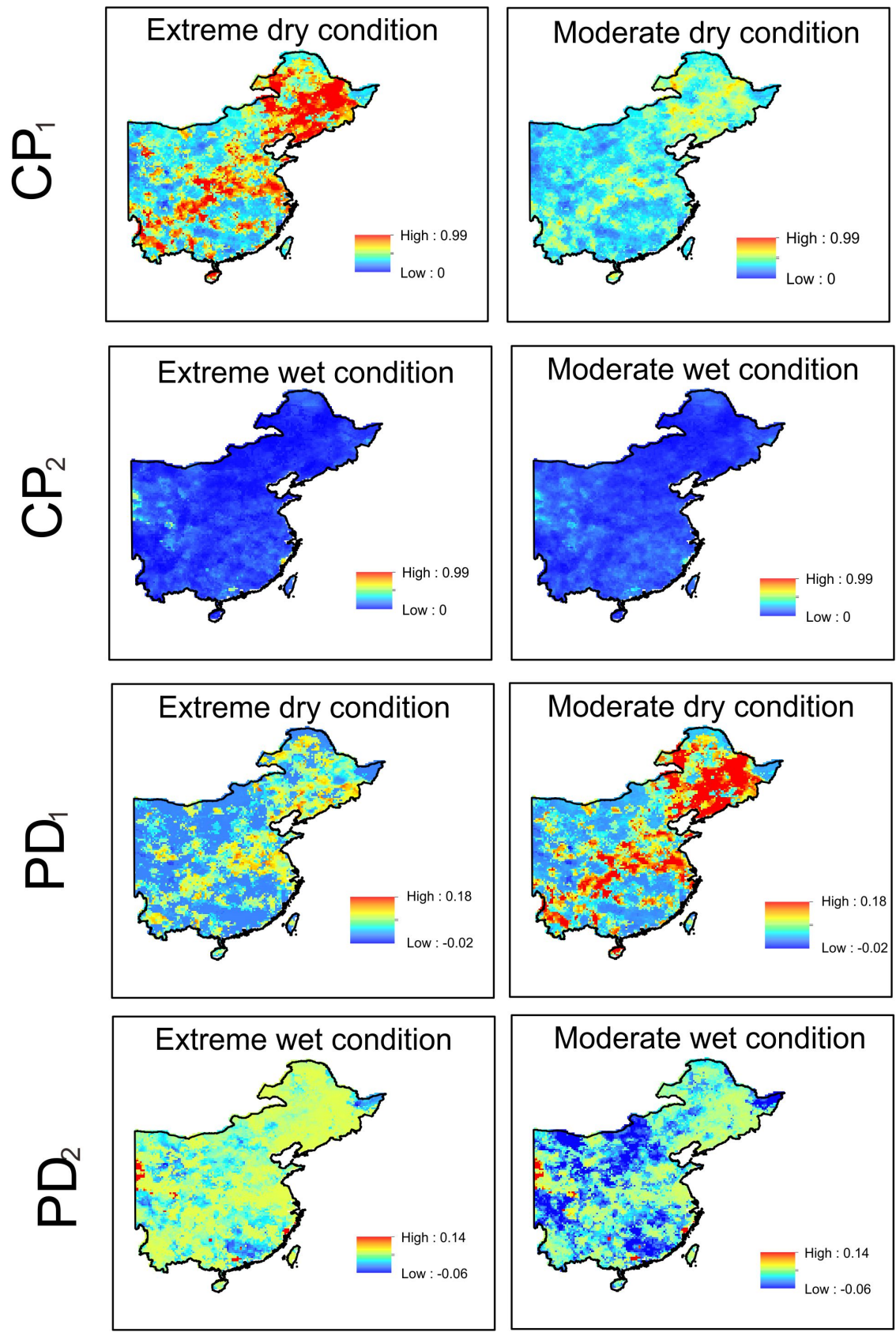

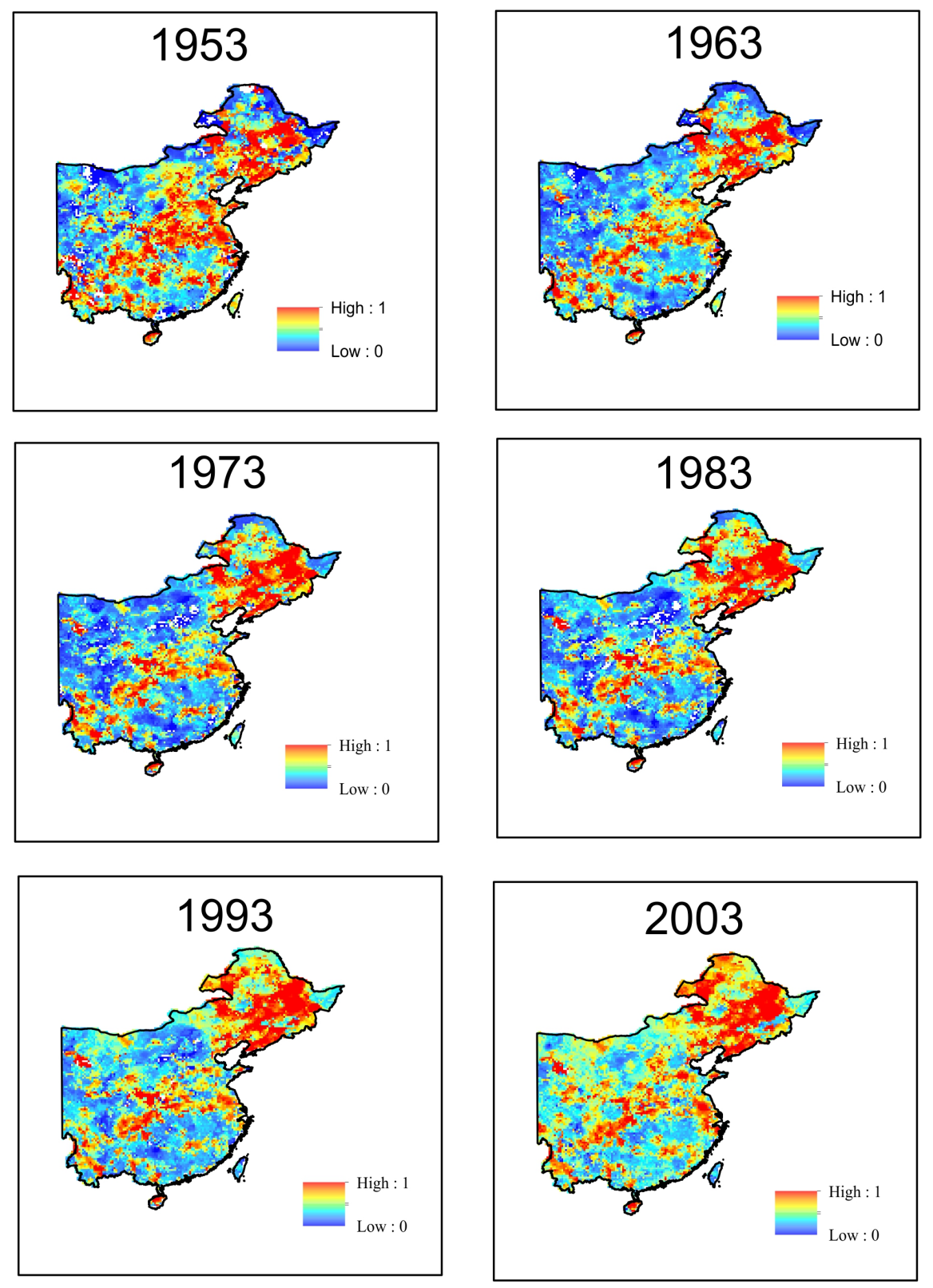

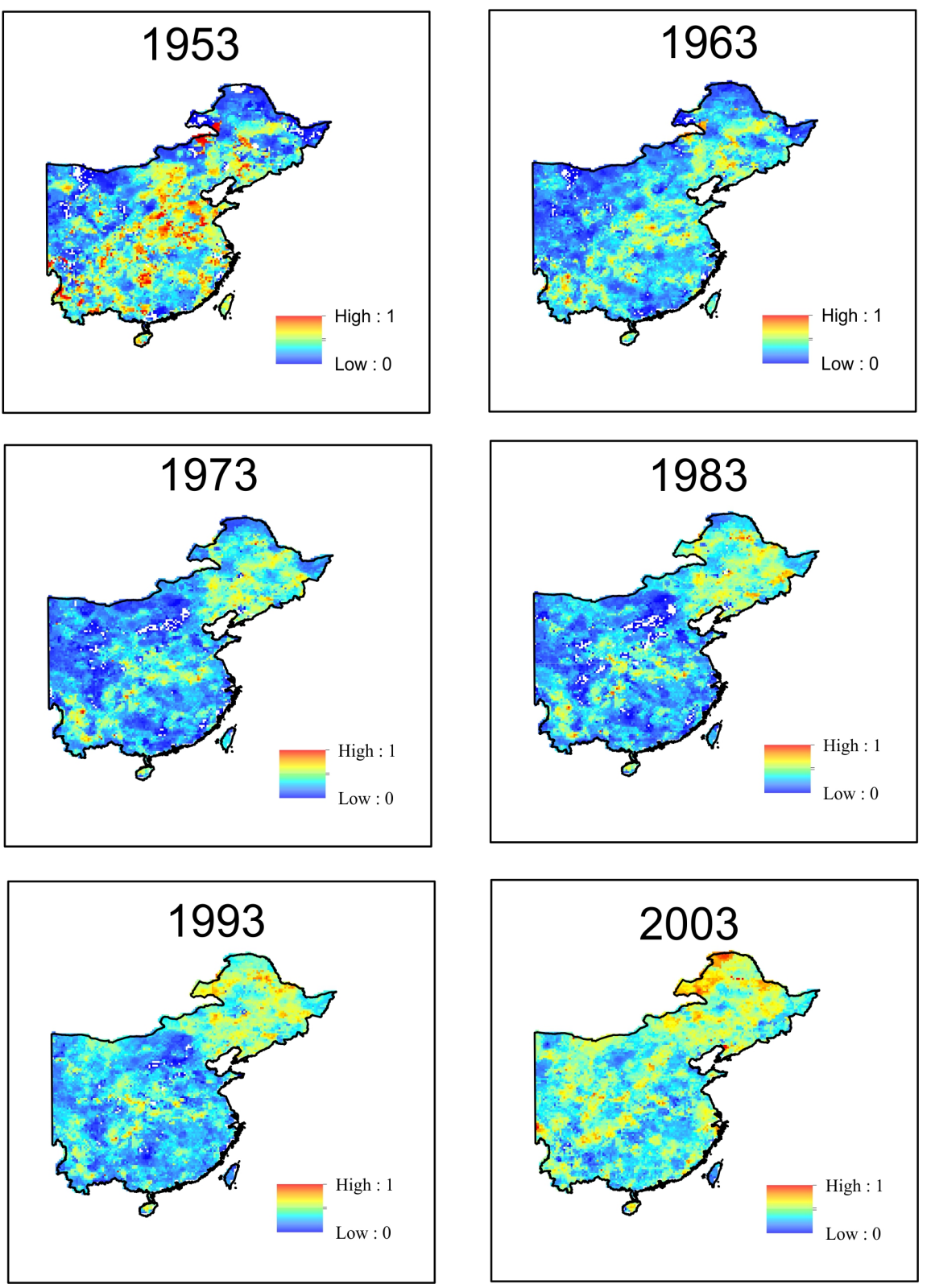

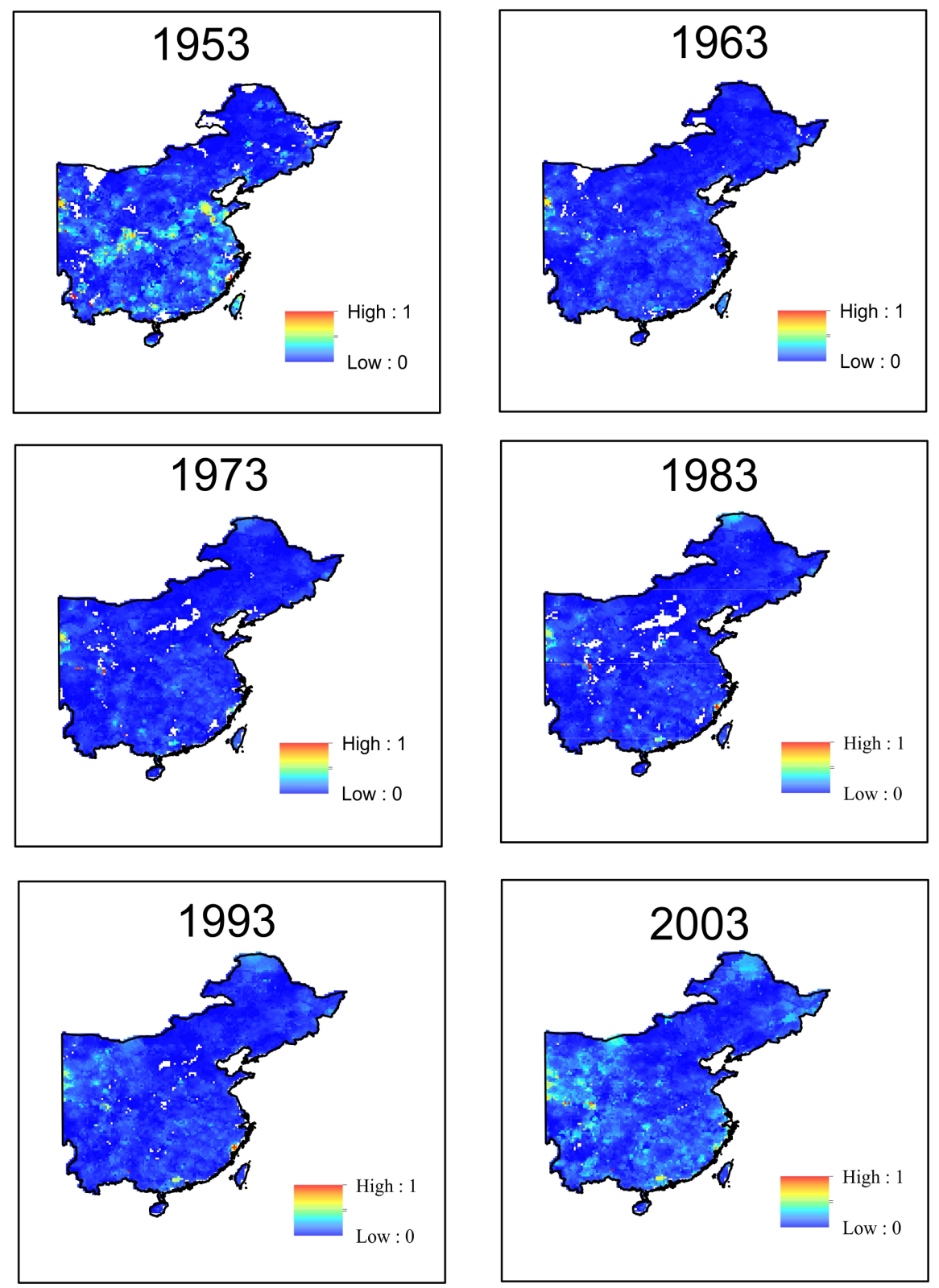

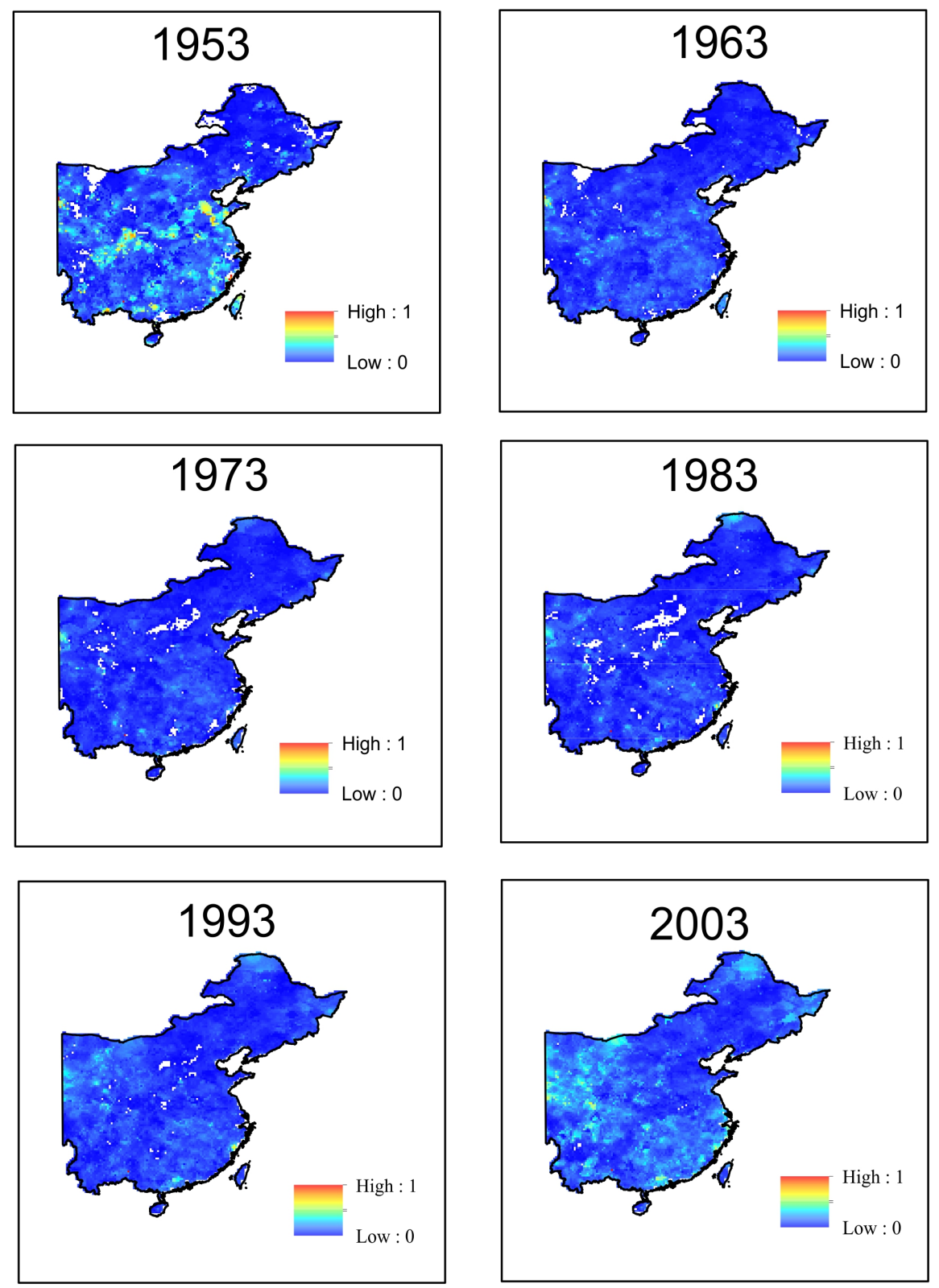

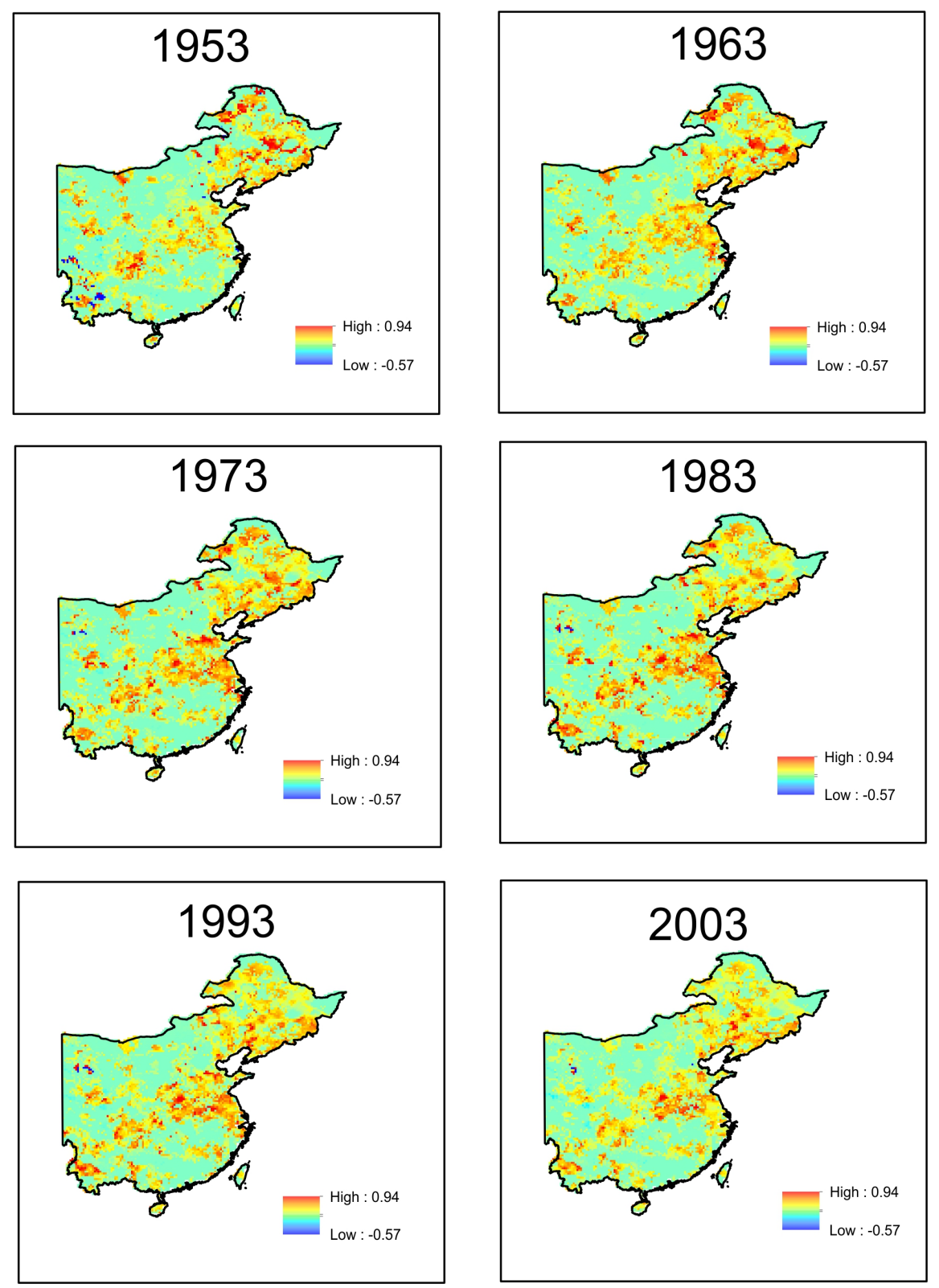

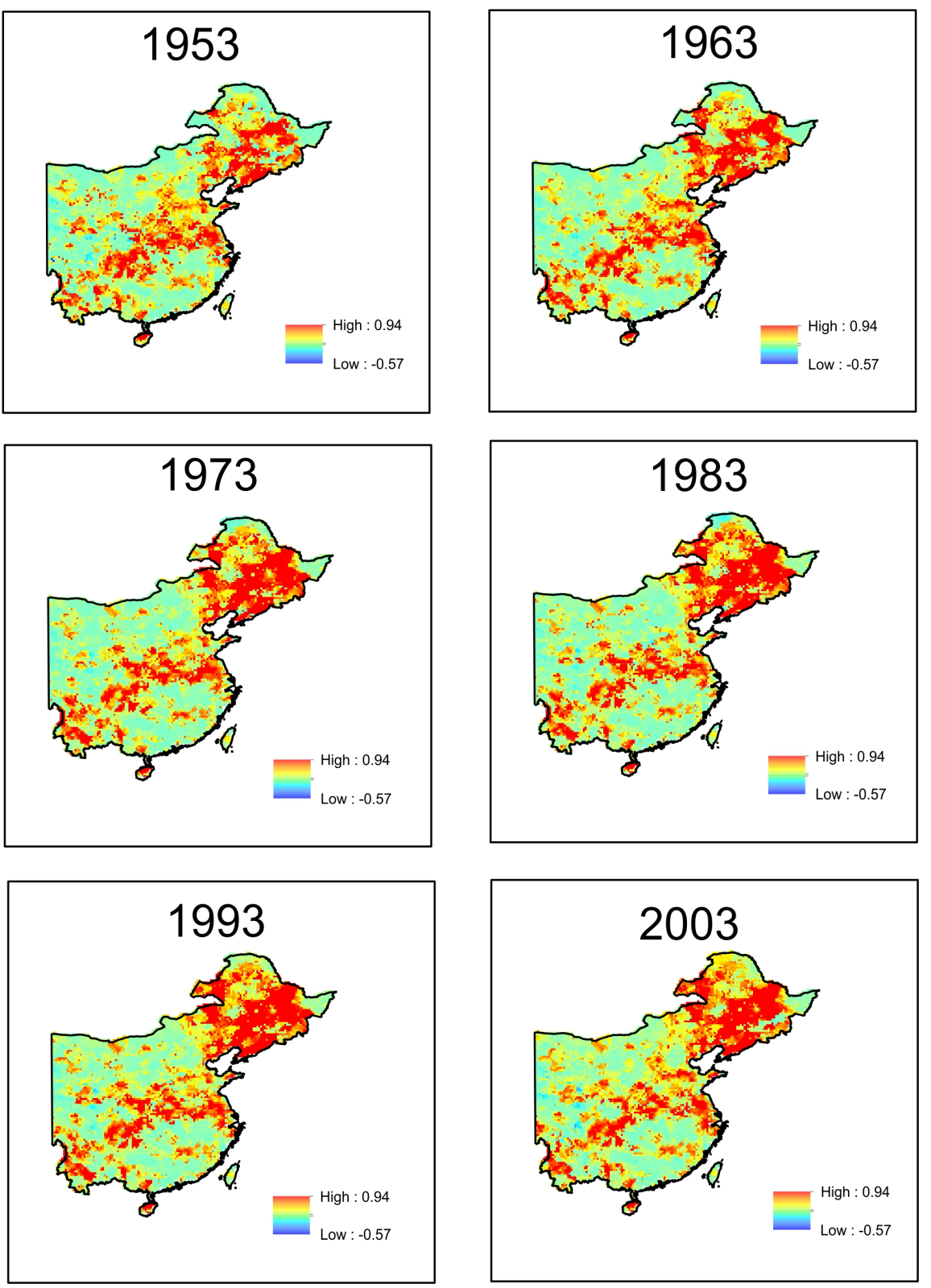

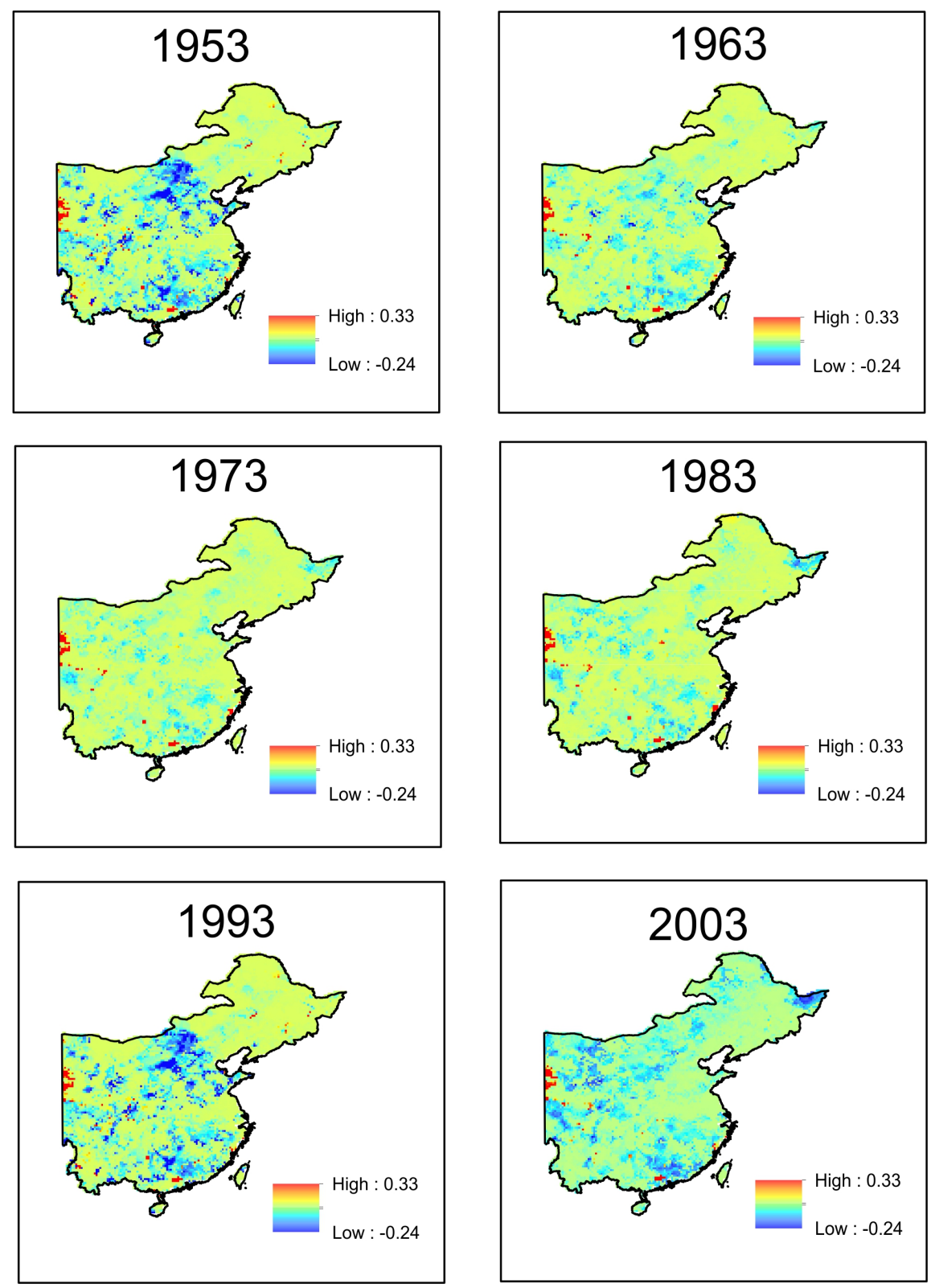

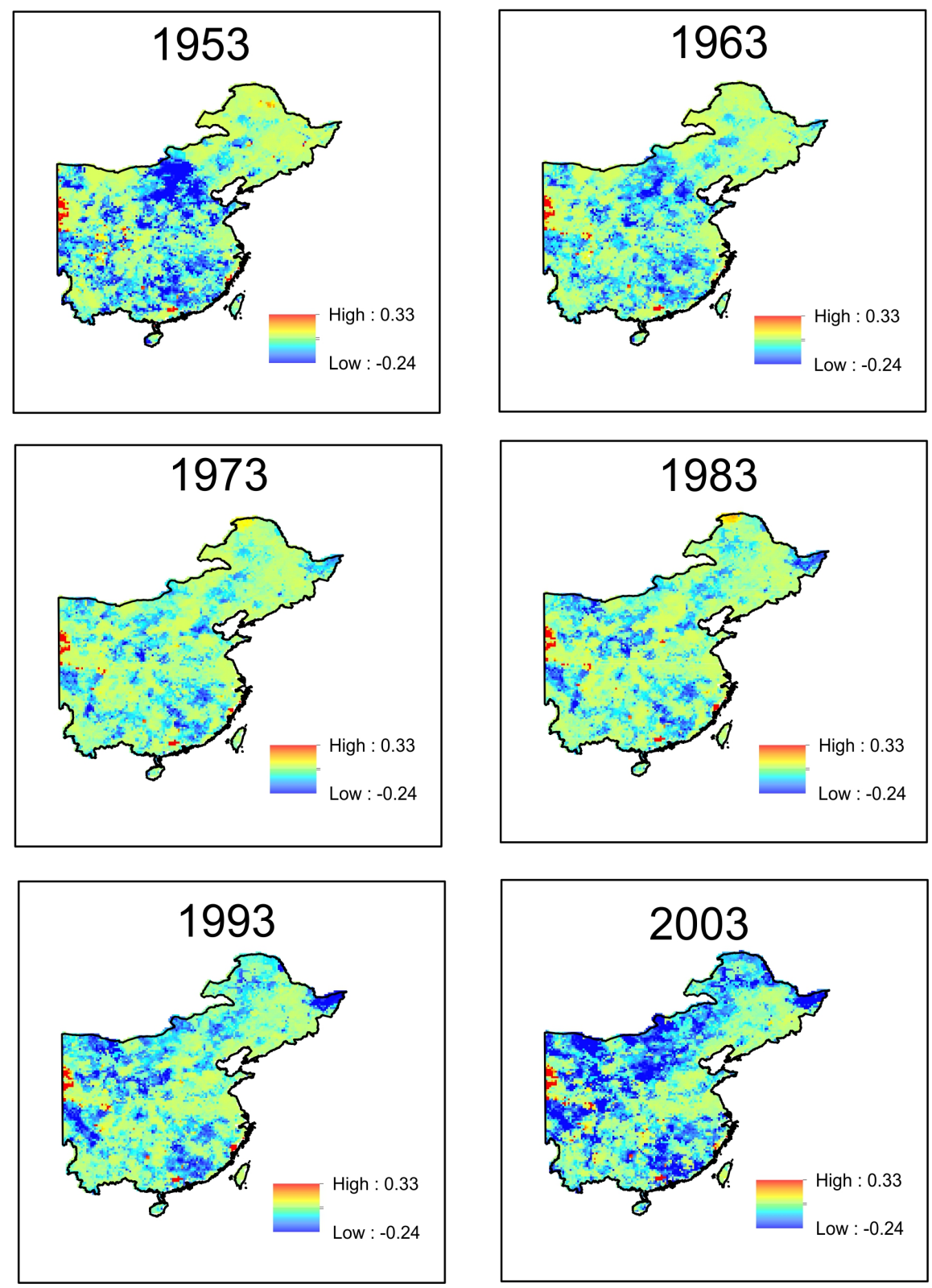


$$
\text { 㳕 }
$$



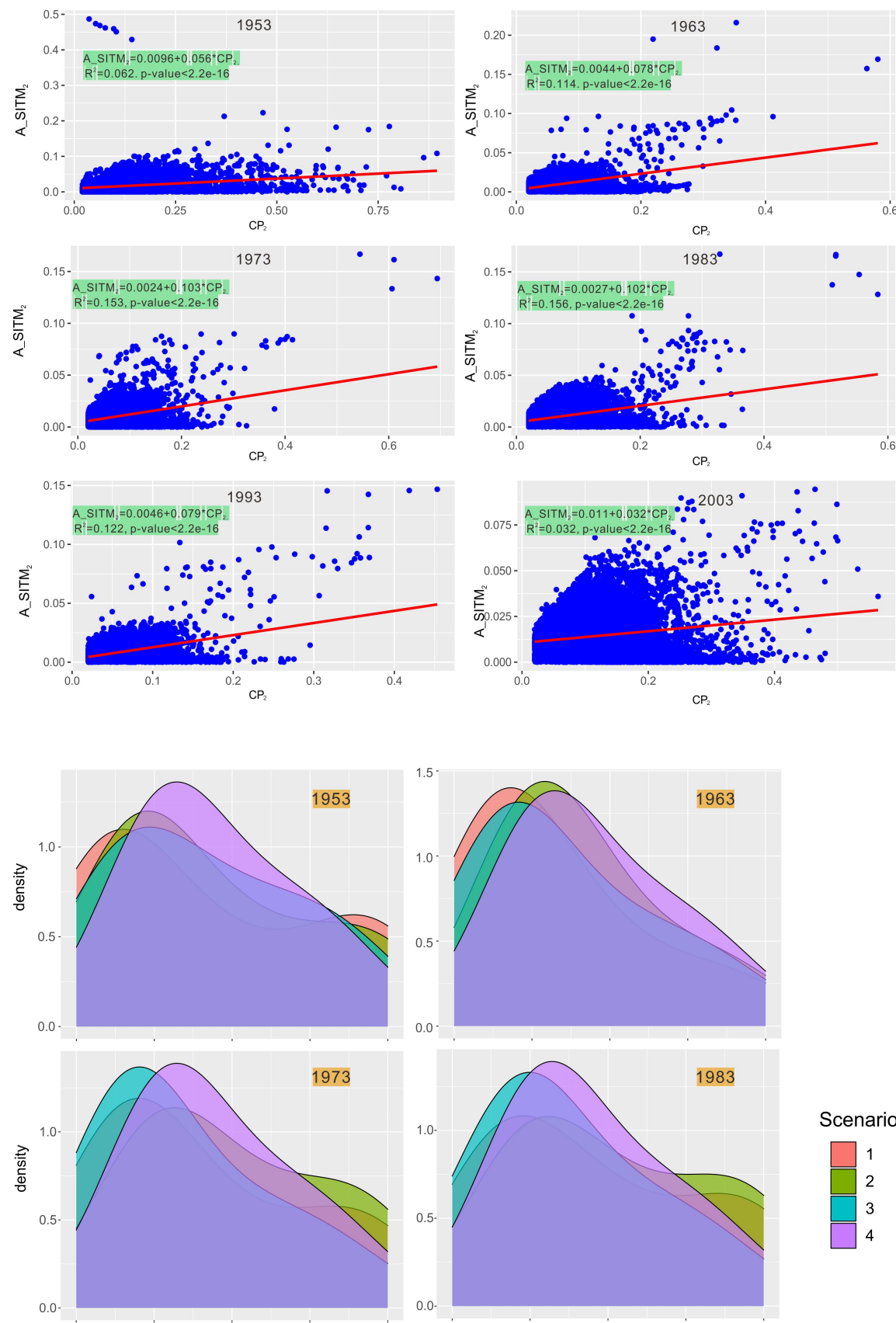

Scenario
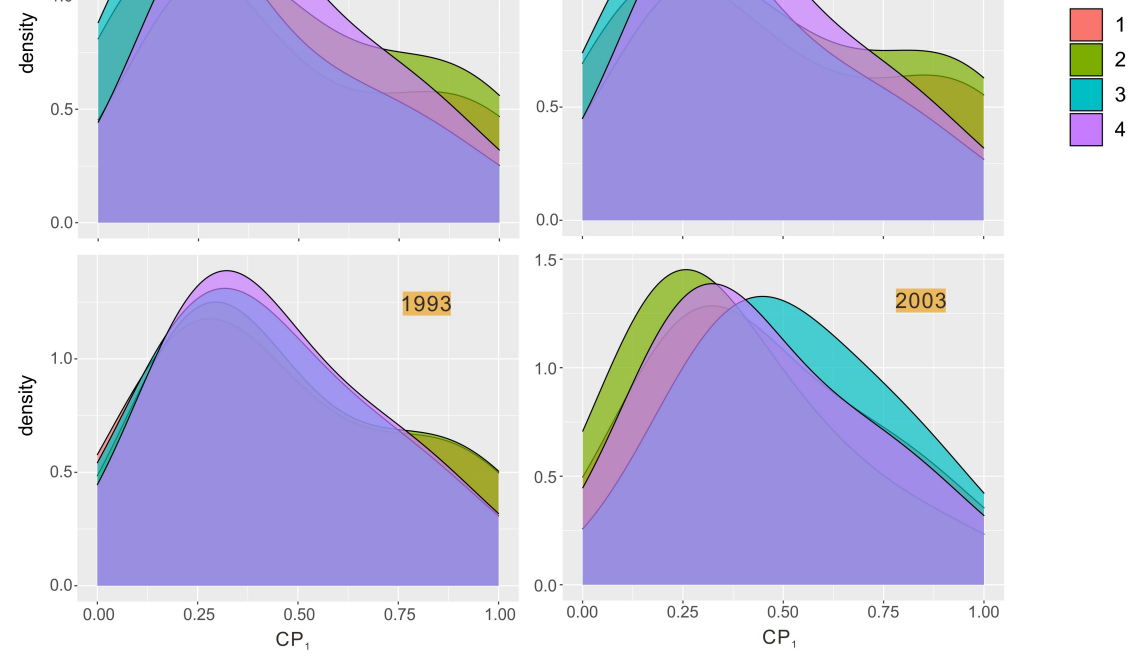

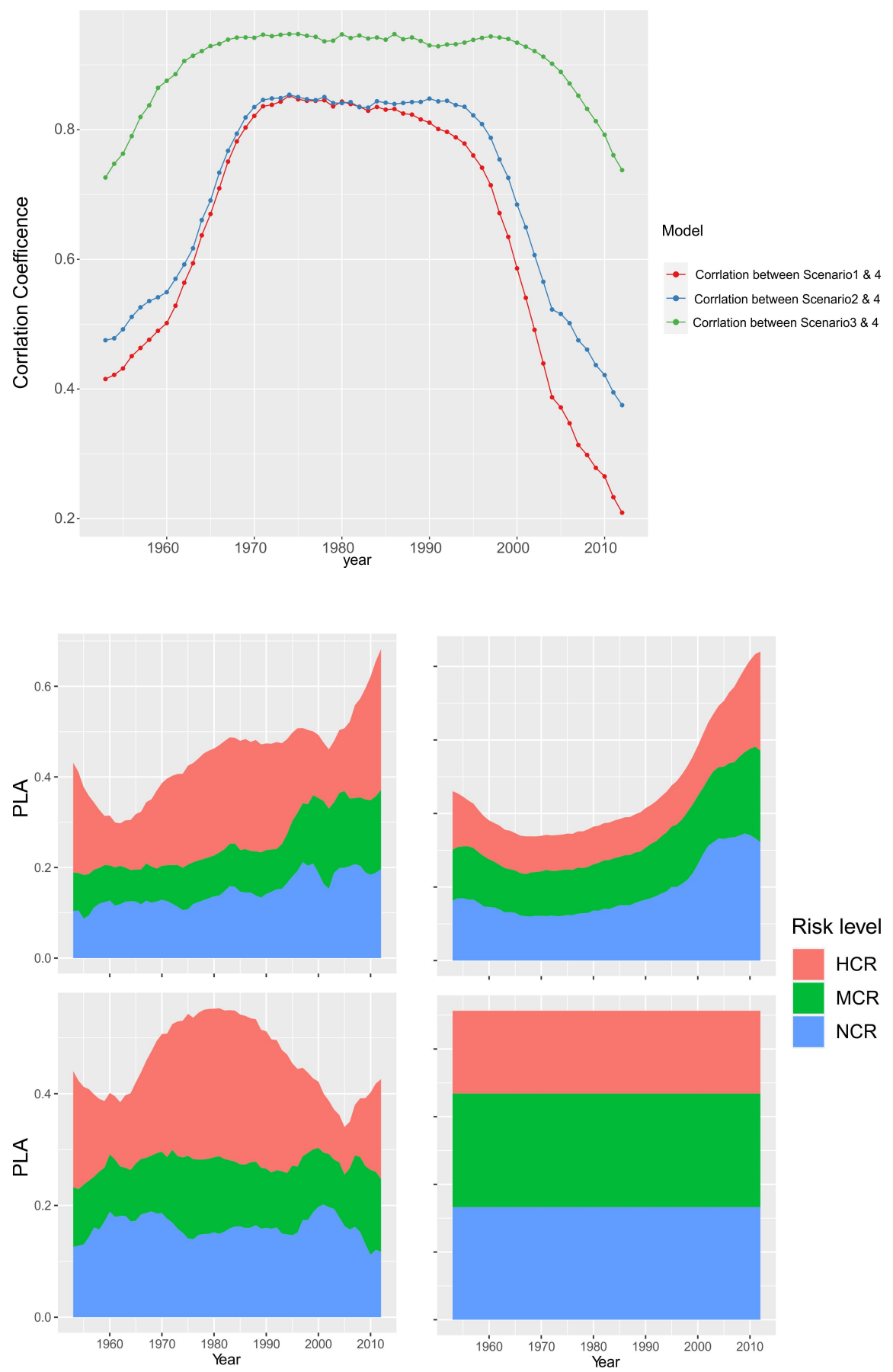

Risk level

HCR

MCR

NCR 